\title{
Severe mitral regurgitation in a woman with a double orifice mitral valve
}

\author{
JACK KRON, ROBERT J STANDERFER, ALBERT STARR
}

From the Department of Medicine, Division of Cardiology; and Department of Surgery, Division of Cardiovascular Surgery; Oregon Health Sciences University, Portland, Oregon, USA

SUMMARY A 64 year old woman with partial atrioventricular canal and double orifice mitral valve presented with severe mitral regurgitation secondary to a torn leaflet. The double orifice regurgitant mitral valve is an unusual finding at operation.

Double orifice mitral valve is an unusual congenital abnormality that is rarely of clinical importance. We describe a patient in whom this finding was associated with severe mitral regurgitation.

\section{Case report}

A 64 year old woman was noted to have a murmur at age 20, but was symptom free until 1977 when congestive heart failure developed. A murmur typical of mitral regurgitation was noted. Her symptoms resolved on digoxin and diuretic treatment. She did well until November, 1983, when symptoms of weakness, abdominal distension, dyspnoea, and palpitation developed. Frusemide and quinidine (for ventricular extrasystoles) were started but when her symptoms progressed she was referred to our institution.

\section{CLINICAL FINDINGS}

Physical examination showed a normotensive female in no distress. Pulse was 66 beats per minute with frequent extrasystoles. Her venous pressure was raised with pronounced V waves. Carotid pulses were normal. The apical impulse was felt in the sixth intercostal space in the midclavicular line, and there was a left parasternal thrill. The first and second heart sounds were normal. The third heart sound was soft. A grade 5/6 harsh pansystolic murmur radiated from the heart apex to the axilla and spine. There was a grade $3 / 6$ harsh systolic murmur at the left sternal border. There was a soft diastolic murmur at the apex. A pulsatile liver was palpable $5 \mathrm{~cm}$

Requests for reprints to Dr Jack Kron, Department of Medicine, Division of Cardiology, Oregon Health Sciences University, 3181 SW Sam Jackson Park Road, Portland, Oregon 97201, USA. below the right costal margin. There was minimal oedema.

The electrocardiogram showed left axis deviation, first degree atrioventricular block, and right bundle branch block. A chest $x$ ray film showed cardiomegaly, prominent pulmonary arteries, and increased pulmonary vascular flow. Laboratory studies were unremarkable.

Cross sectional echocardiography (Fig. 1) showed left atrial, right atrial, and right ventricular enlargement; an ostium primum type atrial septal defect; and a cleft anterior mitral leaflet. A contrast study demonstrated right to left shunting across the atrial septal defect. At retrospective examination of the echocardiogram two separate mitral valve orifices could be seen in the parasternal long axis right ventricular inflow view.

Cardiac catheterisation demonstrated raised right heart pressures, increased right atrial oxygen saturation and mild arterial desaturation. The pulmonary: systemic blood flow ratio was 1.9:1.

Left ventricular cineangiography showed normal wall motion with evidence of a gooseneck deformity of the left ventricular outflow tract and severe mitral regurgitation. There was left atrial and right ventricular enlargement. Early appearance of contrast in the right atrium confirmed the presence of an atrial septal defect. Coronary angiography was normal.

\section{FINDINGS AT OPERATION}

The heart was explored through a lateral right atrial incision. The tricuspid valve annulus was considerably dilated with a cleft in the septal leaflet extending to the septal rim. The valve was grossly incompetent. A $3 \mathrm{~cm}$ diameter ostium primum defect was present. The mitral valve was fully viewed through an incision in the atrial septum (Fig. 


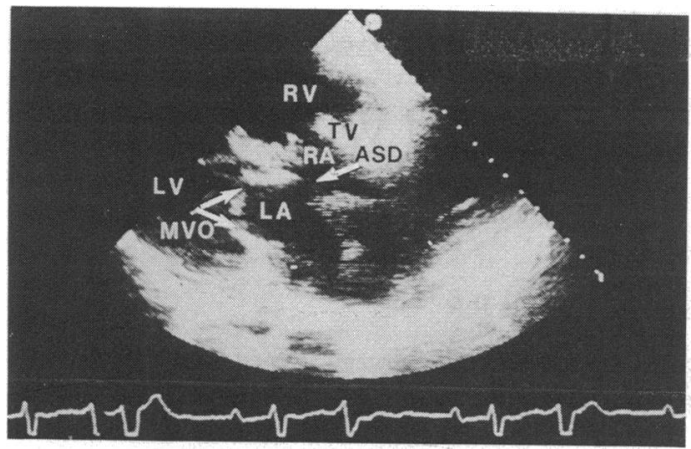

Fig. 1 Cross sectional echocardiogram (parasternal long axis, right ventricular inflow view) showing both the atrial septal defect (ASD) and the dual orifice mitral valve. $L A$, left atrium; $L V$, left ventricle; $M V O$, mitral valve orifice; $R A$, right atrium; $R V$, right ventricle; $T V$, tricuspid valve.

2). It was composed of an oval annulus with two complete orifices divided by a transverse bridge of leaflet tissue. Each orifice had its own slightly eccentric placed papillary muscle. From each muscle, chordae tendineae radiated in a parachute fashion to the leaflet edges. The posterior orifice was approximately two thirds the diameter of the anterior orifice and was fully competent. The anterior orifice had a cleft in its anterior leaflet opposite the cleft in the septal leaflet of the tricuspid valve. On the anterior ostial margin of the cleft there was a single ruptured chord and a thickened flail leaflet. A regurgitant jet was demonstrated in this segment when the left

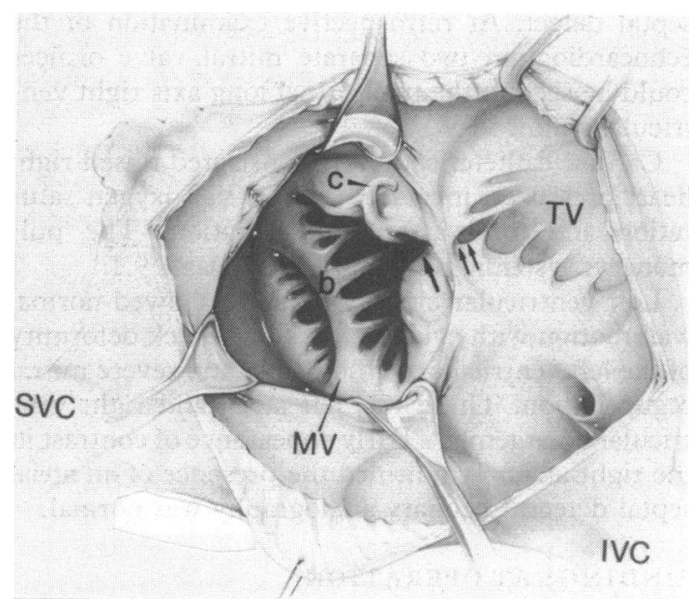

Fig. 2 Drawing of the in situ surgical findings. The mitral valve is viewed at operation through a surgically enlarged ostium primum atrial septal defect via a right atrial incision. Mitral valve (MV) with torn chord (c) and cleft anterior leaflet (large arrow) and bridging tissue (b).TV, tricuspid valve with cleft septal leaflet (small arrows). SVC, superior vena cava. IVC, inferior vena cava. ventricle was filled with saline solution.

Repair of the ruptured chord by reimplantation did not restore valve competence. Cleft closure with interrupted sutures also failed to restore complete competence. We considered closure of the larger orifice, but believed that the secondary orifice would be inadequate to maintain flow. Therefore both mitral valve orifices were excised and were replaced with a 3M Starr-Edwards 6120 valve. The cleft in the septal leaflet of the tricuspid valve was closed. Tricuspid competency was restored by reestablishing a near normal annular shape and size by use of a $28 \mathrm{~mm}$ Carpentier tricuspid ring. The ostium primum defect was closed with a patch of autogenous pericardium secured by running suture.

\section{Discussion}

Double orifice mitral valve is a rare disorder that was first reported by Greenfield in $1876^{1}$; over sixty cases have since been described. ${ }^{2-13}$ This abnormality is rarely of clinical importance, ${ }^{7}$ and most cases are recognised at operation or necropsy. It occurs as an isolated lesion or in association with other anomalies such as atrioventricular canal, bicuspid aortic valve, coarctation of the aorta, transposition of the great arteries, patent ductus arteriosus, supravalvar mitral stenosis, subaortic stenosis, secundum atrial septal defect, and ventricular septal defect. ${ }^{3461013}$ Endocardial cushion defects are present in $25-50 \%$ of cases, ${ }^{4} 714$ with double orifice mitral valve being seen in $3-10 \%$ of all cases of persistent atrioventricular canal. ${ }^{31314}$ The case we describe is unusual because of the patient's age and mode of presentation. The oldest patient in the Wakai and Edwards necropsy study was 13 years old and all the others were $<2 \frac{1}{2}$ years old. ${ }^{3}$ In the largest series reported all patients were $\leqslant 20$, and the double orifice valve was generally an incidental finding. ${ }^{13}$ Clinically important mitral regurgitation $^{56915}$ has been diagnosed on the basis of a geometrically deformed valve, ${ }^{9}$ anterior mitral leaflet fenestration, ${ }^{5}$ or abnormal origin of the chordae tendineae and papillary muscles. ${ }^{6}$ This is the first report of a case in which a flail leaflet due to a ruptured chorda tendineae caused severe mitral regurgitation.

\section{ANATOMICAL AND EMBRYOLOGICAL FEATURES}

Ilbawi et al reported eight patients with double orifice mitral valves. ${ }^{14}$ Four had an intermediate atrioventricular canal without a cleft mitral leaflet while the others had ostium primum defects. The former group had intractable congestive heart failure and did not survive operation, whereas the latter 
group recovered. These findings accord with those in a later series. ${ }^{313}$ All five of the cases in the Wakai and Edwards series were associated with complete or intermediate atrioventricular canals and all the patients died of congestive heart failure or postoperatively. ${ }^{3}$ The 11 cases in the Warnes and Somerville series were associated with ostium primum defects and tended to have a better course. ${ }^{13}$ This resembles our patient, who first presented in her fifties.

There is some disagreement about the embryological origin of this lesion. Wimsatt believed that the accessory orifice was the result of abnormal fusion between the anlagen of the medial and lateral mitral valve leaflets. ${ }^{16}$ Lewis, however, believed that the accessory orifice was the result of developmental arrest and persistence of the left part of the common atrioventricular canal, resulting in an accessory orifice in tissue destined to become a mitral leaflet. ${ }^{16}$ Ancalmo et al supported the latter theory because endocardial cushion defects are often found in association with this lesion. ${ }^{7}$

\section{ANGIOGRAPHIC AND ECHOCARDIOGRAPHIC FINDINGS}

Our patient showed the typical gooseneck deformity of the subaortic region of the left ventricle seen in ostium primum defects caused by abnormal placement of the anterior mitral leaflet. ${ }^{1718} \mathrm{~W}$ arnes and Somerville and Somerville and Jefferson have described two rows of fine crenations in the medial region of the left ventricle, representing the double orifice. ${ }^{1318}$ Echocardiography will often define both orifices. ${ }^{1418}$ If an ostium primum defect is present, the fishmouth appearance of the normal mitral valve is replaced by a triangular configuration with separation of the anterior components of the anterior leaflet. Although the double orifice was not recognised before operation in our patient, on retrospective examination of the echocardiogram the angulated parasternal long axis view showed two orifices (Fig. 1).

\section{SURGICAL CONSIDERATIONS}

The surgical approach to patients with mitral valve abnormalities associated with endocardial cushion defects has recently been reviewed. ${ }^{1419}$ Our approach resembles that of the Mayo Clinic group. ${ }^{20}$ It has been our experience that when the cleft in the mitral valve has been left intact, or only partly closed, reoperation has been required because of progressive mitral regurgitation. ${ }^{19}$ Therefore, we usually close the cleft with interrupted sutures if the mural leaflet component of the mitral valve is of adequate size (that is, greater than one third of the circumference of the annulus). In cases where the mural leaflet component is less developed, the cleft has been left partly or completely open; however, as noted earlier, this has given less than satisfactory results. In cases where the cleft is left open, invagination of the base of the commissure may provide better apposition and competence. If not, mitral valve replacement is probably indicated.

Double orifice mitral valve is a rare lesion that can complicate the surgical repair of endocardial cushion defects. ${ }^{1418}$ Diagnosis should be considered in patients who have evidence of an ostium primum atrial septal defect. Cross sectional echocardiography and left ventricular angiography can be useful in establishing the diagnosis.

\section{References}

1 Greenfield WS. Double mitral valve. Transactions of the Pathological Society of London 1876; 27: 128-9.

2 Schraft WC Jr, Lisa JR. Duplication of the mitral valve. Case report and review of the literature. Am Heart F 1950; 39: 136-40.

3 Wakai CS, Edwards JE. Pathologic study of common atrioventricular canal. Am Heart $\mathcal{F}$ 1958; 56: 779-94.

4 Rosenberg J, Roberts WC. Double orifice mitral valve. Study of the anomaly in two calves and a summary of the literature in humans. Arch Pathol 1968; 86: 77-80.

5 Kenaan G, Neufeld HN, Deutsch V, Shem-Tov A. Isolated congenital double-orifice mitral valve. Report of a case. Isr $\mathcal{J}$ Med Sci 1974; 10: 743-7.

6 Mercer JL, Tubbs OS. Successful surgical management of double mitral valve with subaortic stenosis. $\mathcal{F}$ Thorac Cardiovasc Surg 1974; 67: 440-2.

7 Ancalmo N, Ochsner JL, Mills NL, King TD. Double mitral valve. Report of a case and review of the literature. Angiology 1977; 28: 95-100.

8 Herskowitz A, Factor SM. Mitral valve duplication associated with membranous septal aneurysm. Embryogenesis of atrioventricular valve duplication. NY State I Med 1979; 79: 260-3.

9 Yurdakul Y, Bilgiç A, Saylam A, Sarioǵlu T, Köşker S, Aytaç A. Congenital double-orifice mitral valve. Report of a case with valve replacement. Fpn Heart $\mathcal{F} 1980$; 21 : 545-50.

10 Tsuchiya K, Iida Y, Shimazu K, Sakai A. A case report of double mitral valve associated with ostium primum defect. Kyobu Geka 1982; 35: 66-9. [In Japanese with English Abstract].

11 Morishita Y, Tabata F, Taira A, Minagoe S. Case of left ventricular-right atrial communication associated with ventricular septal defect and double orifice mitral valve. Kyobu Geka 1983; 36: 919-23. [In Japanese with English Abstract.]

12 Edwards BS, Edwards WD, Bambara JF, Van Der Bel-Kahn J, Bove KE, Edwards JE. Anomalies of the left atrium and mitral valve. Arch Pathol Lab Med 1983; 107: 29-33.

13 Warnes C, Somerville J. Double mitral valve orifice in atrioventricular defects. Br Heart f 1983; 49: 59-64.

14 Ilbawi MN, Idriss FS, DeLeon SY, et al. Unusual mitral valve abnormalities complicating surgical repair of endocardial cushion defects. F Thorac Cardiovasc Surg 1983; 85: 697-704.

15 Schlesinger Z, Kraus Y, Deutsch V, Yahini JH, Neufeld HN. An unusual form of mitral valve insufficiency simulating aortic stenosis. Chest 1970; 58: 385-8.

16 Wimsatt WA, Lewis FT. Duplication of the mitral valve and a rare apical interventricular foramen in the heart of a yak calf. Am f Anat 1948; 83: 67-107.

17 Criley JM, French WJ. Cardiac catheterization in adults with congenital heart disease. Cardiovasc Clin 1979; 10(1): 173-211.

18 Somerville J, Jefferson $\mathrm{K}$. Left ventricular angiocardiography in atrioventricular defects. Br Heart F 1968; 30: 446-57.

19 Abbruzzese PA, Livermore J, Sunderland CO, et al. Mitral repair in complete atrioventricular canal. $\mathcal{f}$ Thorac Cardiovasc Surg 1983; 85: 388-95.

20 McGoon DC, Puga FC. Atrioventricular canal. Cardiovasc Clin 1981; 11(2): 311-22. 